\title{
THE USE OF SUSTAINABLE LIVELIHOODS FRAMEWORK IN EVALUATING FISHERY POLICIES IN PANGKOR ISLAND, MALAYSIA
}

\author{
${ }^{1}$ Stella Ho Siew Neo*, ${ }^{2}$ Jamilah Mohamad \& ${ }^{3}$ Nurulhuda Binti Mohd Satar \\ (*First author) \\ ${ }^{1}$ Institute of Advanced Studies, Universiti Malaya \\ ${ }^{2}$ Department of Geography, Faculty of Arts and Social Sciences, Universiti Malaya \\ ${ }^{3}$ Department of Economics, Faculty of Economics and Administration, \\ University of Malaya \\ (stellah@siswa.um.my, jamilahmd@um.edu.my, nurulhuda@um.edu.my) \\ DOI: https://doi.org/10.22452/jati.vol23no2.6
}

\begin{abstract}
The marine fisheries sector contributed 1.4\% to Malaysia's Gross Domestic Product (GDP) in 2016, of which $76 \%$ is contributed by coastal fisheries sector. Twenty-four percent of this coastal sector output is contributed by the State of Perak, where Pangkor Island is located, making Perak the major contributor to the fisheries sector of Malaysia. This article aimed to identify the gap between development policies implemented and sustainable outcomes achievement, and subsequently provide suggestions for future adjustments to the sector development policies. The gaps identified include the difference between (1) improvement in the quality of human capital through workshops to improve income level and the actual output enjoyed by fishermen due to the financial limitation; (2) desired outcome of aquaculture project and the actual benefits seen due to limited physical, human and financial capital; (3) improvement of physical capital such as housing area and the financial capital available to service mortgage and replace equipments; and (4) livelihood strategies adopted and the fishermen desired livelihood outcome. A few recommendations were presented to reduce the above mentioned gaps, which include (1) strengthen the current structures and processes to ensure desired outcome of each policies and projects are achieved; (2) encourage the involvement of other operators on the island in moving towards improving
\end{abstract}


the livelihood of fishermen; and (3) a long term plan of changing the culture of "hand to mouth" through education.

Keywords: sustainable development, Pangkor Island, coastal fisheries, livelihood strategies

\section{Introduction}

The fisheries sector in Malaysia plays a significant role in the country's development as it contributes not only to the GDP of the country, it is also an important source of protein (based on the Malaysian food culture), contributes to Malaysian exports to countries such as Japan, Taiwan and Singapore, provide job opportunities to groups such as fishermen, seafood processing workers, fisheries related administrators, fish mongers, as well as having domino effects on the other industry, such as sardine processing factories, boat manufacturers and fishing equipment manufacturers.

Marine waters can be categorized into four fishing zones, namely Zone A (0-5 nautical miles from shore), Zone B (5-12 nautical miles), Zone C (12-30 nautical miles), Zone C2 (30- Exclusive Economic Zone) and Zone C3 (high sea) (Johari, 1996), refer to Figure 1 for clearer illustration. Zone A is reserved solely for small scale fishermen, Zone B for owner-operated commercial fishing vessels of less than 40 Gross Register Tonnage (GRT), Zone C for commercial fishing vessels of more than 40GRT and Zone C2 as well as C3 for deep-sea fishing vessels of 70GRT and above (Food and Agriculture Organization, 2001). This research focused on fishermen who carry out their activities within the coastal area, i.e. Zone A, B and C.

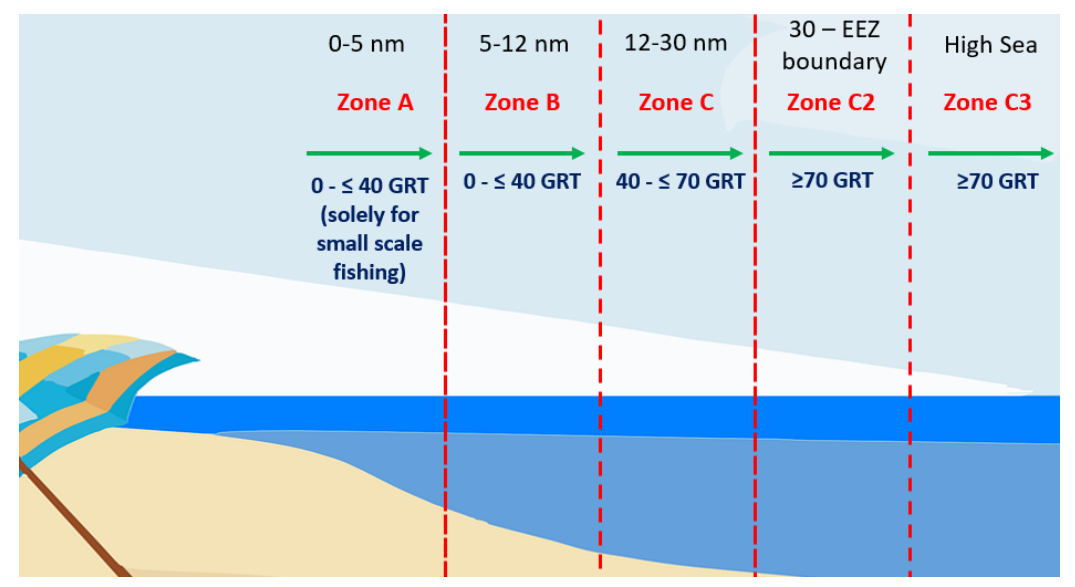

Figure 1: Fishing Zones 
There are a few agencies and organizations working together to support the development of the fisheries sector in Malaysia. These organizations include Department of Fisheries Malaysia (DOF), Fisheries Development Authority of Malaysia (LKIM) and Fishermen Associations (FA). The functions and the organization of each of these organizations can be seen in Figure 2.

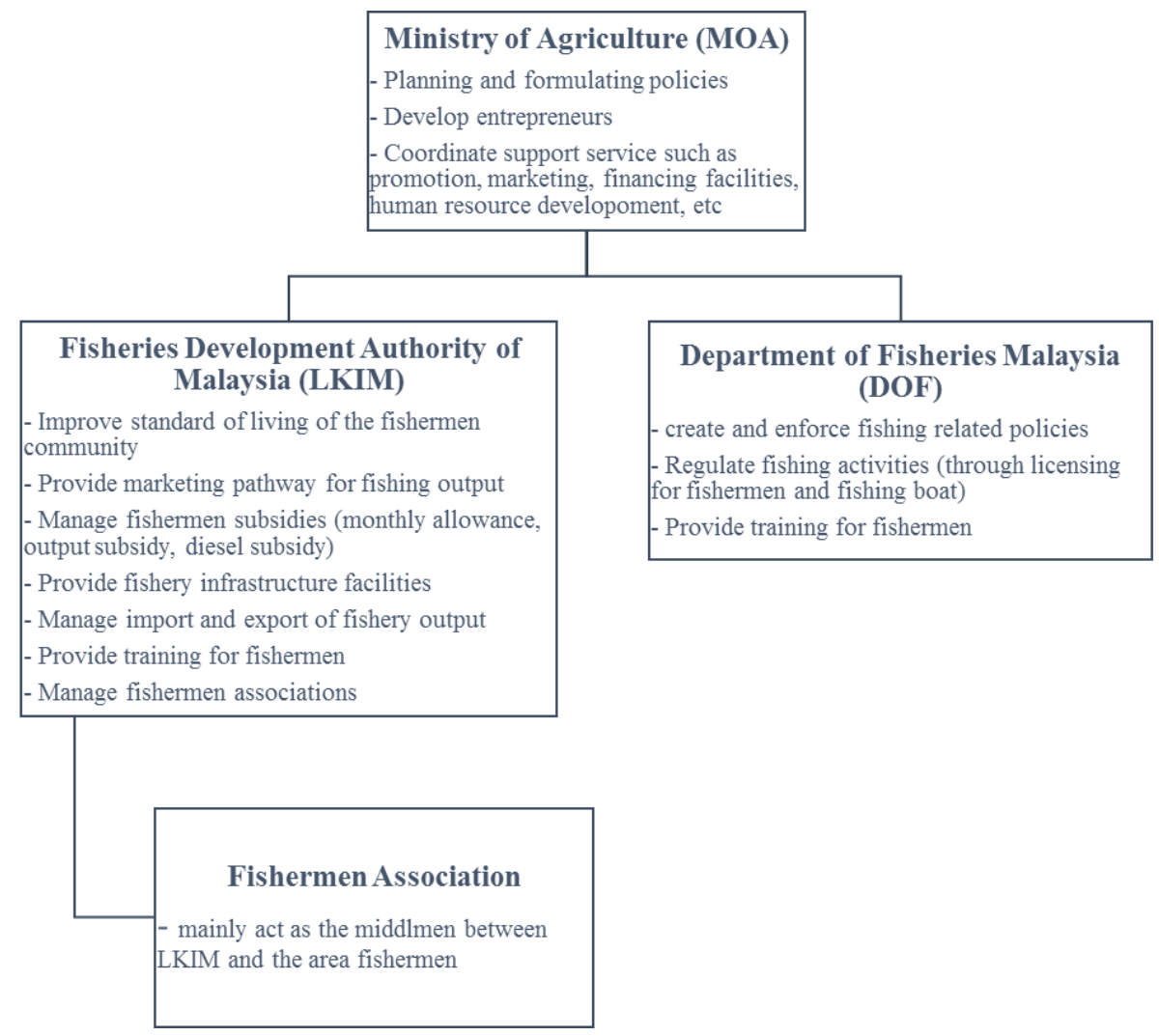

Figure 2: Organizations/Agencies Supporting Fishery Industry

In year 2016, there were a total of 98,279 local fishermen and 34,026 foreign fishermen (mainly from Thailand, Indonesia, Vietnam) in Malaysia, of which 2,542 (2.6 percent of local fishermen) and 1702 (5 percent of foreign fishermen) are located in Manjung District, Perak, where Pangkor Island is located (Department of Fisheries of Malaysia, 2016). Continuous reduction in the number of local fishermen and increase in the number of foreign fishermen in Manjung District is shown in Figure 3. The reason for the change in the number of fishermen will be discussed in findings section. On Pangkor Island 
alone, they were 897 registered fishermen, consisting of 635 Bumiputras (indigenous population, which includes the Malay population), 198 Chinese and 64 Indians in year 2014 (Fishermen Association of Pangkor Island, 2014). This ratio is considered to be common in Malaysia as Malays are known to be seafarer whereby their livelihood or their way of earning a living are historically closely related to the sea (Idris \& Harun, 2004).These fishermen were mainly scattered around the fishing villages of Teluk Dalam, Sungai Pinang Kecil, Sungai Pinang Besar and Teluk Gedung as these areas allowed the fishermen to anchor their fishing vessel at the back of their house, while seashore or beach areas were mainly for tourism purposes.

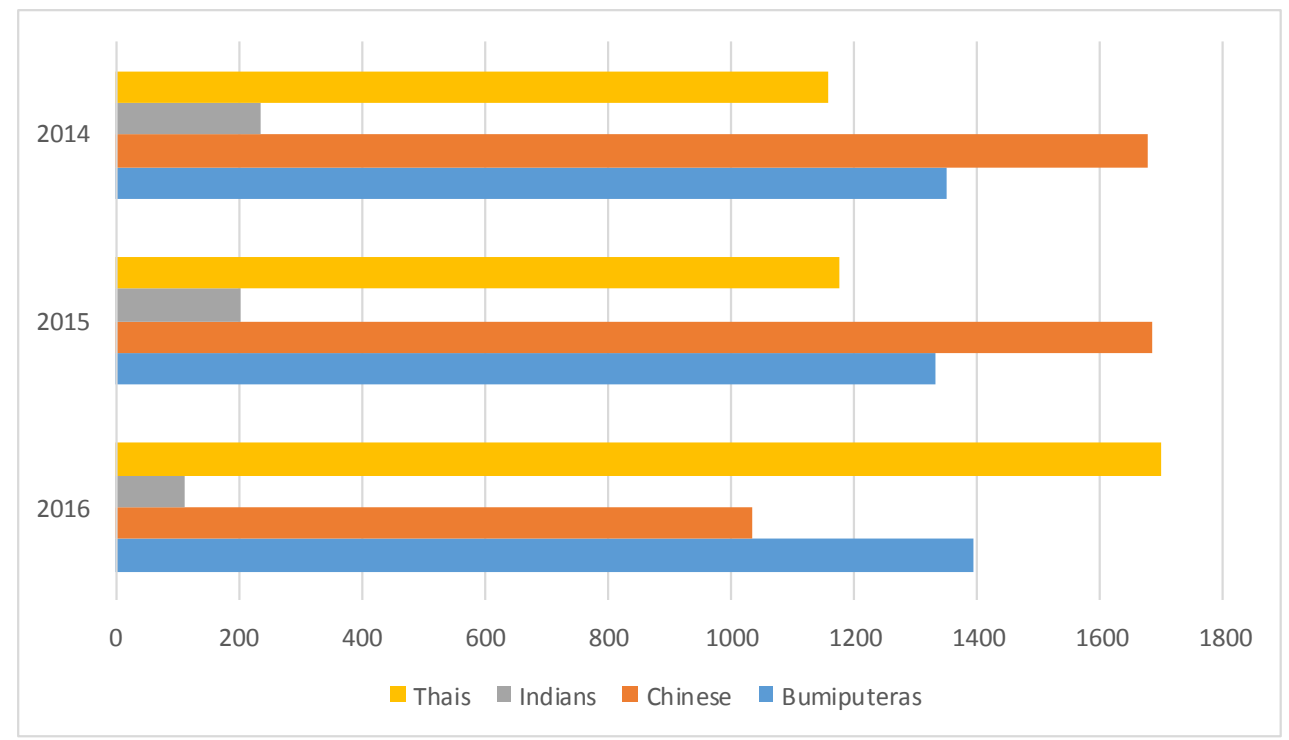

Figure 3: Numbers of Fishermen Working on Licensed Fishing Vessels in Manjung District

(Source: Adapted from Department of Fisheries of Malaysia [2016].)

\section{Theoretical Framework and Literature Review}

Chamber and Conway (1992), who came up with the most commonly used definition of sustainable livelihoods, stated that "a livelihood comprises the capabilities, assets and activities required for a means of living, while a sustainable livelihood will mean the ability to cope with current livelihood and at the same time, able to provide sustainable livelihoods opportunities for the next generations". In 1998, Institute of Development Studies (IDS) had presented a more comprehensive and shorter definition of sustainable 
livelihoods, i.e. "a livelihood comprises the capabilities, assets and activities required for a means of living. A livelihood is sustainable when it can cope with and recover from stresses and shocks, maintain or enhance its capabilities and assets, while not undermining the natural resource base" (Scoones, 1998). However, sustainable livelihoods vary from one individual or community to the other due to different sustainable outcome objectives (DFID, 1999). Hence, there is no standardized definition for it.

A sustainable livelihood framework works as a basis to analyse livelihood of a community, and ultimately allow the authority, policy maker, academician and other relevant parties to identify where help and intervention can be made (Farrington, Carney, Ashley, \& Turton, 1999). The first "people oriented" study on the poorer group of the $21^{\text {st }}$ century were originated from Chambers and Conway in 1992. This framework has set a foundation for the development of other livelihoods frameworks mainly by development agencies. In year 1993, Oxfam, a leading United Kingdom (UK) charity organization in fighting poverty used sustainable livelihood framework to determine its aims, improving its project strategies and providing the most appropriate staff training (OXFAM, 1998). Moving on, in year 1994, a US based non-governmental organization, Cooperative for Assistance and Relief Everywhere, formally known as Cooperative for American Remittance to Europe (CARE), had formed a slightly more comprehensive sustainable livelihood framework which they referred to as Household Livelihoods Security (HLS), which identified three main attributes of sustainable livelihood, i.e. human capabilities, accessibility to both tangible and intangible assets, and the availability of economic activities to generate income (CARE, 2002). In 1999, Department for International Development (DFID) produced a more comprehensive sustainable livelihood framework, aimed at increasing the effectiveness of the agency's poverty reduction projects (refer to Figure 4). DFID focused not only on the importance of people-centred policies, but also policies that is responsive (involving the poor in decision making to better understand their challenges), applicable at multi-levels, conducted in partnership (involved both public and private sector), sustainable (includes economic, institutional, social and environmental sustainability) and dynamic (DFID, 1999). For the purpose of this research, the DFID Sustainable Livelihoods Framework was used as the basis of data collection and analysis. 

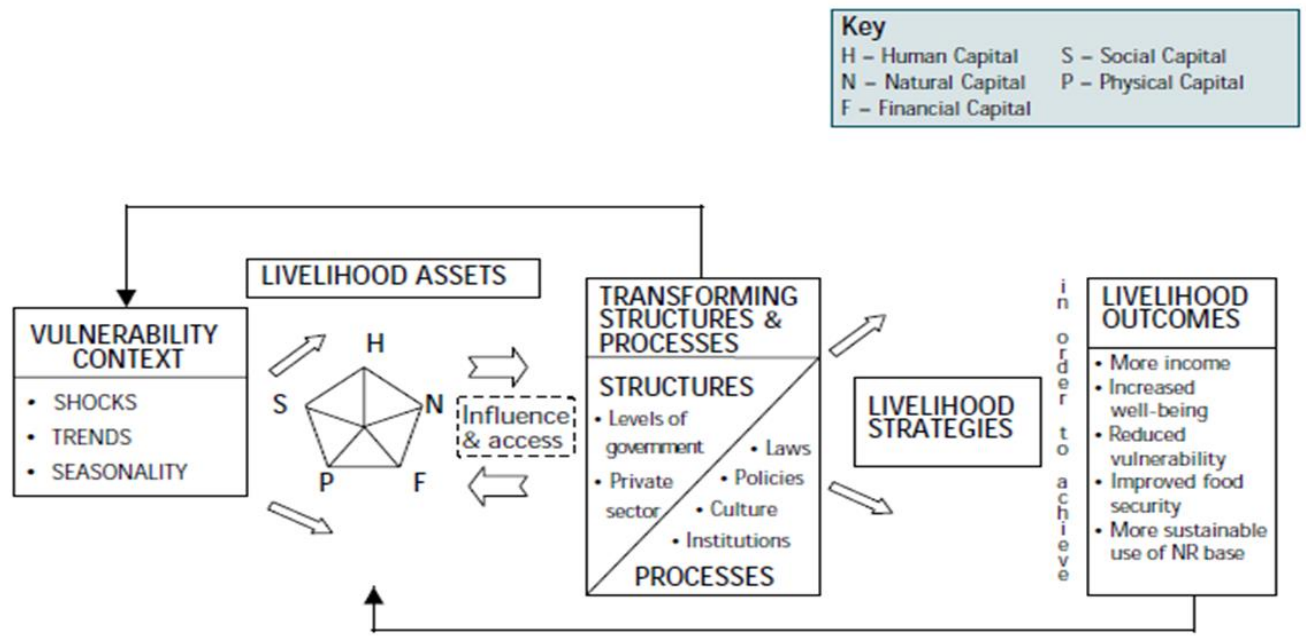

Figure 4: DFID Sustainable Livelihoods Framework (DFID, 1999)

Many researches on sustainable livelihoods have been undertaken in the past. One such study was done in the rural area of northern China by Zhong, Blaxland and Zuo (2015), which showed that despite the achievement of China in reducing poverty rates over the years, the poverty rate in China remained as high as 13.4 percent in the rural population and about 10 percent of China's population as a whole. The researchers concluded that the poverty rate remained high mainly due to a lack of social and economic resources.

Another livelihood research done in India was by Joseph (2015). His research focused on the fishery industry, whereby he looked into the effect of modernization in the fishery industry on traditional fishermen and boat owners in India and revealed the need for striking a balance between ways of improving fishery output and sustaining livelihood of small scale or traditional fishermen.

Similar modernization happened in Nha Phu Lagoon, Vietnam, whereby the introduction of technology and advanced fishing techniques had indeed improved the livelihood intensification level of the coastal fishermen who has existing assets which allowed them to take advantage of the advanced technology hence become wealthier, but had caused the poorer fishermen community to be in debt as they took up loans to acquire the technology (Nguyen, 2014).

In Malaysia, one of the studies on sustainable livelihoods carried out in year 2016 by Masud, Kari, Yahaya and Al-Amin (2016) among communities on Tioman Island Marine Park, Redang Island Marine Park, and Tinggi Island Marine Park reported that the introduction of Marine Park has resulted in 
economic development on all three islands, with the respective communities' standard of living improving in terms of physical and social assets. However, not much of improvement was seen in the sense of human, financial and environmental assets development (Masud et al., 2016).

Another research done among the traditional fishermen in Terengganu, where the researchers reported that the government had undertaken an artificial reef development program with the aim of improving economic conditions of the traditional fishermen, but the aim has yet to be achieved as the regression results shows that the artificial reef areas is negatively correlated with the fishermen's income in almost all districts of Terengganu studied, besides Besut (Islam, Noh, Sidique, Noh, \& Ali, 2014).

Therefore, it is clear that each research focuses on different areas sustainable livelihoods, based on what was needed. For this preliminary study, it was aimed to identify the gap between fisheries policies implemented on fishermen of the Pangkor Island in particular and the sustainable outcomes achieved, which could be used by other researchers in finding appropriate policies to fill in the gap.

\section{Methodology}

The Pangkor Development Plan 1999-2015 and the Guidelines of Development Plan Implementation by Manjung District Council were scrutinized and reviewed. Policies related to fishermen were identified and converted into interview questions to study the actual results of the development project from the fishermen's point of view. Qualitative research method were adopted through open-ended interviews with pre-prepared guided questions (refer to Table 1) were carried out in Bahasa Malaysia (the local language) to ensure a better understanding of the questions. This method was chosen as the fishermen community are more comfortable with sharing information through story telling.

Fishermen were contacted through phone calls, appointments were made, and interview sessions were conducted. Content analysis approach were adopted to analyse data collected. Data were then transcribed, coded and analysed at the same time as the data collection process. The researcher then decided which interviewees were to be called again for further data mining. Thick description was carried out throughout the entire data collection and analysis process. Triangulation process was carried out to validate and shed light on the researcher's perspective of data collected, and the theorizing process. 
Interviewees includes the Chairman of Pangkor Fishermen Association and the "pengurus besar" (general manager) of LKIM. As for the fishermen, those who work in the coastal area and has been a fisherman on the island for five years and above were targeted and selected through random sampling technique, whereby every fifth in the list were interviewed. In terms of sampling size, 10 out of 550 fishermen were chosen for this research as saturation level was achieved, whereby similar information was shared.

\section{Table 1: Guided Open-ended Interview Questions}

\section{Sample categories: Fishermen}

Sample size: 10; duration: 20 minutes each interview; sample questions:

1. How much do you earn per month on average from fishing?

2. Which Zone do you carry out your fisheries activities?

3. What are the fishing method you normally used?

4. How ready are you in trying out new ways of fishing and processing seafood?

5. Do you think aquaculture fisheries can increase your monthly income?

6. Are you a member of the Fishermen Associations?

7. What kind of support do you get from LKIM and the Fisherman Associations?

8. What kind of challenges do you face as a fisherman on this island?

Sample categories: "Pengurus besar" of LKIM and the Chairman of the Fishermen Associations Sample size: 2; duration: 45 minutes each interview; sample questions:

Similar to the questions posted to fishermen, plus a few more strategic questions:

1. What are the current development policies, projects and support available for fishermen?

2. What are the challenges of carrying out the development policies, projects, and support?

3. Will aquaculture fisheries be a good alternative to fisheries since Zone B output has reached Maximum Sustainable Yield (MSY) and it could have happened to Zone A too?

4. Is there any policies to fight against pollution?

\section{Research Findings}

\section{Vulnerability Context}

\section{Seasonality}

Weather and tide level have always been the main concerns of the fishermen. These have caused the fishermen output to vary from month to month, and their incomes to vary from RM0 to RM500 per boat per day. Hence, sometimes income generated from fisheries activity is not even enough to cover daily expenses on basic necessities. However, all interviewees shared that none of them change their fishing area or method in accordance to the change of fish price in the market to increase their income level, or at least, to deal with the problem of shortage of income. On the other hand, the interview with the 
"pengurus besar" of LKIM shows that the fishermen's monthly allowance of RM200 has helped to reduce the severity of the problem of income shortage.

\section{Trends}

All the interviewees raised their concerns about the illegal, unrecorded and unreported (IUU) fishing carried out by fishermen mainly from Thailand and by some locals as well. LKIM has done its part by announcing that only those who reported their catch will get to claim diesel and petrol subsidies. The Malaysian Maritime Enforcement Agency (MMEA) has arrested many who performed IUU. Besides, statistics by the Department of Fisheries (2016), as shown in Figure 3, revealed that the number of local fishermen has reduced. The same trend is seen on Pangkor Island. Fishermen interviewed said that most of the younger generation would rather work in the tourism industry rather than be a fisherman, and they will not encourage their children to be fishermen when they grow up as well. If this trend were to continue, supply of fisheries output in Malaysia would be affected.

\section{Natural Disaster}

This element does not seem to cause much concern among all interviewees. Due to the strategic location of Pangkor Island, which has protected them from the tsunami a few years ago, and consistent support from the authority, have resulted in the fishermen's lack of awareness on how serious potential disasters could have affected them, as all the fishermen agreed that they will decide on going to the sea or not based on their own weather forecast and experience, and one of the interviewees even said that he will still go to the sea even if the weather is not very pleasant as he needs the income. As mentioned earlier, even though fishing can be a high risk occupation due to regular change of weather, the fishermen have become less sensitive to the risks involved as all the interviewees mentioned that they understand the risk they are taking, but that is their life as fishermen or "anak nelayan". This is even more evident when all the interviewees mentioned that they do not have any contingency plan, if disasters were to strike. With regard to this, the general manager of the LKIM mentioned that they have made it compulsory for all the registered fishermen to buy insurance, and the premium to be paid is deducted from the fishermen allowance one a year. 


\section{Livelihood Assets}

The asset pentagon consists of the human capital, natural capital, financial capital, physical capital and social capital. The findings regarding these aspects are deliberated below.

\section{Human capital}

Nine fishermen mentioned that they do not have any skills or knowledge to generate income from other vocations besides being a fisherman even though five of them agreed that they have attended many workshops. Various workshops related to improving fishing methods, seafood processing industry, trawl (fishing net) repairing methods and entrepreneurship were carried out by the LKIM and FA in the past as mentioned by the general manager of LKIM and the president of FA. These workshops managed to attract the interest of the fishermen, but only those with sufficient financial capital and are willing to change were able to apply what they had learnt and benefited from it. Fishermen who did not attend any workshop mentioned that they were neither informed nor selected. This issue will be further discussed under transforming processes and structures.

\section{Natural capital}

The most important natural capital for coastal fishermen on Pangkor Island is the relatively unpolluted waters around Pangkor Island and availability of fisheries output. However, coastal fisheries sector has been heavily exploited and over-saturated beyond sustainable levels in most areas of Peninsular Malaysia as compared to deep-sea fisheries sector which still has room for development (Biusing, 2001; Food and Agriculture Organization, 2001). Hence, aquaculture was introduced to the fishermen few years ago. However, most fishermen confirmed that they cannot start aquaculture farming because the water salinity level around Pangkor Island is high, i.e. ranges from 28.51 to 30.85 during September 2017 (Godon, Mohamed, Gani, \& Johan, 2018) . Only one aquaculture owner concluded that a few types of fish like snappers and groupers can survive in saline water. However, he decided to leave the industry and started the homestay business as the return on investment was too low. Besides that, courses on using solar energy to process fisheries output was introduced to the fishermen too to overcome the issue of seasonality, fishing trend and natural capital. However, this is a capital intensive activity, 
hence only one fisherman managed to make use of it with the support of financial capital. Furthermore, not many fishermen have capitalized on the waters surrounding the island by starting business in marine tourism-related activities even though the tourism industry is growing on Pangkor Island as they do not have access to a passenger boat.

\section{Financial capital}

On average, the fishermen's earnings from fishing activity alone are about RM1500 to RM2000 per month, which is inadequate to support a family of five. In terms of household income, most of the interviewees avoided this question, or mentioned an insignificant amount. The FA is providing support for loan applications to help expand their business, however, not many have applied because they deemed that the application process is too complicated, and they are not able to comprehend the long application form. Petrol and diesel subsidies, together with monthly allowance, are provided by DOF through LKIM as mentioned earlier, but according to the fishermen, not everyone has received them, even though they have registered with the FA. The response given by the authority is that, as long as the fishermen are registered with the FA, the three forms of assistance would be automatically given to them. The general manager of LKIM further explained that retired fishermen continue to ask for the monthly allowance as they treat those allowances as their retirement fund.

\section{Physical capital}

The Pangkor Development Plan 1999-2015 has allocated RM50,600,000 for the development of infrastructures and utilities. This is the total physical resources available to the fishermen to improve their livelihoods. Two fishermen have benefited from the upgrading of houses, which include replacing ceiling, expansion of existing house, and some maintenance work, while two other fishermen have been relocated to temporary settlement houses while their existing houses are being rebuilt. However, there were grouses regarding the unstable power supply in the settlement houses which have caused their electrical appliances to malfunction. The rest of the interviewees are still waiting for their turn, if there is. Besides that, new apartments have been built and sold to fishermen at below market price, i.e. RM35,000 per unit. Some fishermen have applied to buy the apartments and waiting to move in. However, the General Manger of LKIM mentioned that the authority will still 
allow the fishermen to purchase those apartments even though he has this concern that some buyers may not pay the instalment accordingly as this is already happening to the terrace houses The main reason for this moves include to beatify Pangkor Island to attract tourist, and to introduce a more decent accommodation to the fishermen community.

\section{Social capital}

Social capital is important for the fishermen to build beneficial network and to have access to other type of capitals too. All fishermen who engaged in fishing for a minimum of 120 days per year are eligible for the Fishermen Card and to be a member of the FA. This membership provides them with a channel to raise their concerns, to be trained and most importantly, to claim subsidies and allowances. Through interview sessions, it was noted that some fishermen are not in the loop of what FA is doing for them, for example fishermen who are staying in Teluk Dalam, as they are not within the network of FA committee members. This situation corresponded to the response they gave on the reason for not taking up courses, i.e. not being informed.

Six fishermen have raised their concerns about not receiving subsidies due to alleged cronyism practised by the community head. This scenario is contributed by the lack of social capital, i.e. lack of appropriate social network within the community. The said fishermen alleged that whenever there are new grants, subsidies, allocations, or even courses, the community head will only choose his pool of participants to be the recipients. Hence, the same group of people will be receiving allocations and courses participation repetitively while others will not come to know about it. To make matters worse, the fishermen also mentioned that a few recipients who received subsidized fishing boats are no longer active fishermen. They will tend to rent it out to other fishermen who did not receive it, or resell the boat.

\section{Transforming Structures and Processes}

\section{Government's subsidy}

According to the Fishermen's Associations Act 1971 Clause 11.2, fishermen, fish processors who derived 60 per cent of their income from the fisheries sector, and those who engaged in the development of the fisheries sector, are all eligible to be members of the FA. This has created dissatisfaction among fishermen as all members are eligible for dividends. All ten fishermen 
mentioned their dissatisfaction in having to share the profits of their hard earned money with the "non-fishermen". However, the general manager of LKIM is of the view that since these non-fishermen have been contributing to the fisheries sector as a whole, their effort should be acknowledged and appreciated.

According to the president of FA, there is such possibility for two reasons. Firstly, information is usually disseminated by the committee members of FA directly to the fishermen, or through the community head. Names of eligible recipients or interested participants will be passed on to FA or LKIM through the same channel. Hence, there is a high possibility that FA committee members might share that information within their limited networks. Secondly, Pangkor Island is considered fortunate, as compared to other fishing villages, Pangkor fishermen received allocations from various sources, i.e. private sector, non-governmental organizations, besides the public sector; and not all the sponsors will go through FA or LKIM to reach out to the recipients. Hence, it is difficult for FA or LKIM to control or to set up a fair selection system. This is in line with the responses given by some fishermen who mentioned that there were incidents whereby allocations went straight to the individual recipients. These types of allocation might come from personal contacts or from their own family members who have access to information.

Three plots of land have been allocated for residential purposes, which is to build ninety-nine units of terraced houses in Pangkor Indah (completed and occupied), apartments in Teluk Gedung (completed but not occupied yet) and Pasir Bogak (pending) to relocate the fishermen. Fishermen who were interested in relocating to the terraced houses need to pay only RM35,000, which is about RM216 per month in instalments. Even though the Pangkor Indah houses have been occupied, a few fishermen felt that its location is not suitable for them. They are used to staying by the sea, where they can anchor their fishing boat right behind their houses. Besides that, four fishermen mentioned that they have not been paying the instalments for the past few months due to low season. Similar conditions might be expected with the apartment units. This may come as a concern to the authorities who have to pump money into the community, but not getting the desired results.

\section{Alternative livelihoods}

The DOF has allocated grants for the fishermen to start aquaculture farming. However, perhaps due to illiteracy, not many fishermen have applied for the said grants due to complicated requirements such as filling up lengthy 
application forms. Besides, the fishermen also mentioned that they are uncertain about the outcome of the aquaculture sector, hence they are not willing to take up the risks involved. As mentioned earlier, a fisherman, who is a university graduate, had made use of the grant provided but after a year, the venture failed

\section{Training}

In terms of other assistance, the general manager of LKIM mentioned that training programs for the wives of fishermen, such as sewing and entrepreneurship classes, had been conducted before. These training programs aim to supplement the fishermen's household income. However, the fishermen interviewed, speaking on behalf of their wives, mentioned that their wives who has started juice stalls or sewing services did not do so solely on the basis of those training programs, but more so due to the skills they have mastered earlier. It seems that Tenaga National Berhad has promised to provide funding for sewing machines, but that assistance has yet to arrive. If the promise were to be fulfilled, it should assist the beneficiaries to make use of the skills and knowledge they have gained from those workshops and overcome the existing financial barriers.

Besides activities for the wives, engine repairing courses have been carried out as well as confirmed by general manager of LKIM and all ten fishermen too. Two fishermen attended the courses, but they found the contents to be very basic. Hence, they could not apply the skills in gaining more side income, instead, they only use the knowledge to repair their own boat engines whenever necessary. A fisherman interviewed confided that he has a certificate in mechanical skills, and he has been earning side income from home based on the skills he had learnt from college too. However, he has not been able to expand his business due to high cost of rent on the island. A similar situation was mentioned by another fisherman who has attended a fibre glass boat making workshop. He has shown his understanding on the costs involved in making a fibre glass boat and estimated profits he can make out of it, and he has even gone further to register his business. However, the limited physical space available on the island causes him to leave the idea aside. 


\section{Marketing mechanism}

The FA has started a new "pasar nelayan" (fishermen's market) aimed at increasing sales revenue. However, according to general manager of LKIM, this market lasted only two months as the market was located within the fishing village, away from the targeted customers. The new plan is to convert this building into a trawl repairing centre. The idea of having the fishermen's market is good for the fishermen to market their catch of the day, instead of going through the middlemen. However, this seems to be another useful project with poor implementation results.

\section{Livelihoods Strategies}

Six fishermen interviewed mentioned that they have changed or multiplied their fishing methods and areas over the years of fishing. This includes, from working for others to operating their own fishing boat, from concentrating fishing activities in one area to venturing to multiple areas, from using one type of fishing gear to using many. The strategies they attempted involve many considerations: (1) they did that as they started to gain experience and confidence over the years, while some mentioned that they had to do so due to erratic fishing output; (2) as living expenses increases beyond their affordability, they had to increase their income; (3) change in the direction of wind and waves; (4) owner of the big fishing boat hired foreign workers as it is relatively cheaper and foreign workers does not have direct family commitment which allowed them to be on the boat for days; (5) some big boats are exploiting Zone A when they are supposed to be operating in Zone C2 and lastly; and (6) some fishing method are indeed easier to manage than others. All the six fishermen agreed that their income has been made a little bit more stable from those actions taken.

Out of the ten fishermen interviewed, only a few have ventured into other industries for side income, one has started his own business in seafood processing mainly "gamat" (sea cucumber), another one was operating a food stall and the third one work as a cleaner in a local hotel. For those who have not seek side incomes, they chose not to do so because of the following reasons: (1) they do not have the human capital, financial capital and social capital to do so; (2) they tried doing business but stop after sometime as the returns were not even enough to cover cost incurred; and (3) they felt no opportunities had come their way as yet. Even so, a few fishermen interviewed disagreed to allow their wives to work in other industries to gain more income 
for the family for the following reasons: (1) they felt women should not be carrying the burden of finding financial means for the family; (2) uncertain working hours of fishermen make it crucial for the women to be at home to take care of the children; and (3) their wives have never work outside before (4) their wives do not have the relevant human capital to work for others.

\section{Livelihood Outcomes}

Interview sessions with the fishermen showed that they are targeting at the following livelihood outcomes: (1) improved wellbeing; (2) sustainable income (3) reduced level of vulnerability; and (4) improved environmental sustainability. These outcomes are in line with the objectives of FA and LKIM.

Three fishermen mentioned that their level of wellbeing, i.e. standard of living, has improved over the years. This happened as they took advantage of the infrastructure, physical development, growth in tourism industry and training programs available. However, others are quite passive about this as their income from fishing activities has reduced and cost of leaving has been increasing over the years. This causes them to discourage their children to be fishermen. Hence, they encourage their children to concentrate on their studies and get a more decent job.

In terms of sustainable income, even though the fishermen mentioned that they would like to have a more sustainable source of income, in the end they ended up contradicting themselves when they mentioned that they are used to living from hand to mouth (the Malay proverb which carries this meaning which they quoted is "kais pagi makan pagi, kais petang makan petang". This saying refers to the proverbial hen which scratches for food in the morning and consume it in the morning, and likewise has to repeat the action in the evening for its evening meal). If this attitude were to persist, this would become a huge barrier for the fishermen to achieve sustainable income. Both the president of FA and general manager of LKIM mentioned that, even though the level of income generated by fishermen is inconsistent, monthly allowances and diesel subsidies provided have contributed towards the fishermen's monthly or even daily expenses.

To reduce the level of vulnerability of fishing activity, a few fishermen vary their fishing areas, methods or gears, while others diversified their source of income as mentioned earlier. However, other fishermen mentioned that they are used to the risk associated with fishing activities as it has become part of their lives. In other words, they have become less sensitive towards the 
weight of risk. Hence, it does not work as a motivator anymore, in fact, it has become a stumbling block towards reducing level of vulnerability.

\section{Discussion}

These research findings show an obvious gap between development policies implemented and the intended benefits of those policies. For example, development policies implemented such as conducting workshops to improve human capital were sometimes found to be less effective in increasing the level of income, while other useful workshops were not effective in improving livelihoods as its implementation were limited by financial constraints. It was mentioned that projects such as aquaculture farming had been limited by the physical conditions of the seawater around Pangkor Island, available skills and knowledge of the fishermen, and again financial capital. Construction of terrace houses and apartments for the fishing community has been limited by bad debts, while the system implemented by FA to have a representative of each fishing village in the committee so that information can be disseminated effectively, is being misused.

Besides that, findings also show some gaps between livelihoods strategies adopted and expected livelihoods outcome. For example, fishermen are aiming at achieving sustainable income and at the same time being comfortable with having enough income to just cover daily meals. In other cases, fishermen are aiming at reducing level of vulnerability while being less sensitive to the high risks carried each day, and not seeking for other vocation.

These gaps have to be reduced by strengthening the transforming structures and processes. The Pangkor Island Development Plan 2016-2020 is now available and the Malaysian Budget 2018 has been announced as well. More development policies have been agreed upon, for example, further improvement of infrastructure to develop the tourism industry, turning Pangkor Island into a duty-free island, and more subsidies promised for the fishermen during low season. Hence, an improved system has been put into place to avoid the same issue from recurring as was the case in the implementation of Pangkor Island Development Plan 2011-2015. Institutions such as FA, LKIM, DOF and even the State Government has to work towards setting up a transparent and effective system to ensure the highest level of benefits to be enjoyed by the fishermen community. For example, a research done on FA shows that the area FA has to be proactive in assisting the local fishermen in improving their income level and economic status, particularly 
FAs, including FA of Pangkor Island, which are not involving in the marketing of fishing output (Othman, 2004).

Besides, as many workshops and training has been conducted but the expected outcome, particularly to improve the livelihood of the fishermen community has not been significant, it is important that the gap between implementation of programs and actual outcome be reduced. For example, seaweed aquaculture in has been proven to helped improving livelihood and household income of the fishermen communities of other part of Malaysia such as Banggi and Kudat in Sabah (Hussin \& Khoso, 2017). At the same time, fish aquaculture such as tilapia aquaculture has been successful in various locations across Malaysia such as Tasik Kenering, Pulau Tioman, etc to diversify source of income to fishermen. Hence, research should be then be done by the authority to find the possibility of these aquaculture to be as successful on Pangkor Island.

In addition, the relevant authority might look into the possibility of rewarding the other stakeholders on the island if they are willing to adopt and train the fishermen community in skills and knowledge needed to work for them. This will play an important role in improving human skills, reducing problem of lacking social capital and financial capital and the saturation level of natural capital. On top of that, this move can reduce the cost of workshops as well.

Thirdly, an exposure to the economic condition beyond Pangkor Island might be important for the fishermen community to get rid of the culture of living from hand to mouth as mentioned earlier. No doubt, culture is the most difficult element to be changed, but some effort has to be put through the education system such as setting up skills-based college on the island or field visits outside of the area. This is seen to be crucial as, based on their expected livelihood outcomes, the fishing community do have the desire of improving their livelihoods level.

\section{Conclusion}

Fishery is an important sector to Malaysia as it is an important source of food and it provides job opportunities not only to the fishermen community but other relevant sectors as well. This makes it crucial to maintain the sustainability of fishery sector and the fishermen community. This paper focuses on the study of the livelihood of coastal fishermen, as coastal fishery output plays a significant role to the fishery sector. The background study shows that the fishery sector is generally maintained by three organizations, 
which include the DOF, LKIM and FA. The number of bumiputeras and foreign fishermen has increased over the years, which ultimately increased the total number of fishermen as a whole, even though the number of fishermen of other races reduces.

This research was carried out based on the DFID Sustainable Livelihoods Framework. As a form of preliminary study, open interview sessions were conducted, targeting at coastal fishermen, general manager of LKIM and Chairman of FA, to identify the gap between fisheries policies implemented on the fishermen of Pangkor Island and the sustainable outcome achieved.

The findings of this research were presented based on the variables introduced in DFID Sustainable Livelihoods Framework. Gaps were identified in a few areas, which include improving the quality of human capital and the desired improvement of income, development projects such as aquaculture farming and limitation of physical, financial and human capital, improvement of physical capital such as housing area and financial capital, as well as the gap between livelihoods strategies adopted and expected livelihood outcome.

A few recommendations were presented to fill in or to reduce the gaps mentioned. These recommendations include strengthening the transforming structures and processes, involving other operators on the island in improving the livelihood of the fishermen community and lastly change of culture through education. Further research will need to be carried out to study the effectiveness of each recommendations.

\section{Acknowledgement}

We would like to acknowledge the financial support provided by the University of Malaya under the Equitable Society Research Cluster (ESRC) research grant RP009G-13SBS.

\section{References}

Biusing, R. (2001). Assessment of Coastal Fisheries in the Malaysian - Sabah Portion of the Sulu Sulawesi Marine Ecoregion. Fish Department Sabah. Retrieved June 26, 2016, from http://www.fishdept.sabah.gov.my/sites/default/files/uploads/fileupload/71/assessment-coastal-fisheries.pdf 
CARE. (2002). Household Livelihood Security Assessments: A Toolkit for Practitioners, Prepared for the PHLS Unit. Tucson, Arizona: TANGO International Inc.

Chambers, R., \& Conway, G. (1992). Sustainable Rural Livelihoods: Practical Concepts for the 21st Century. IDS Discussion Paper No. 296. Brighton: IDS. Department of Fisheries of Malaysia. (2016). Annual Fisheries Statistic 2016. Department of Fisheries of Malaysia. Retrieved September 17, 2017, from http://www.dof.gov.my/index.php/pages/view/3049

DFID. (1999). Sustainable Livelihood Guidance Sheets. Eldis. Retrieved November 20, 2015, from http://www.eldis.org/vfile/upload/1/document/0901/section2.pdf

Farrington, J., Carney, D., Ashley, C., \& Turton, C. (1999). Sustainable Livelihoods in Practice: Early Applications of Concepts in Rural Areas. Natural Resource Perspectives, 42, 1-15. Retrieved from http://dlc.dlib.indiana.edu/dlc/bitstream/handle/10535/4235/42sustainable-livelihoods-in-practice-ruralareas.pdf?sequence $=1 \&$ isAllowed $=y$

Fishermen Association of Pangkor Island. (2014). 2014 Annual Report of the 35th AGM. Pangkor Island: Fishermen Association of Pangkor Island.

Fishermen's Associations Act 1971.

Food and Agriculture Organization. (2001). Information of Fisheries Management in Malaysia. Food and Agriculture Organization (FAO). Retrieved December 15, 2015, from http://www.fao.org/fi/oldsite/fcp/en/mys/body.htm

Godon, E., Mohamed, K. N., Gani, M. A., \& Johan, S. (2018). Study of dissolbed Copper (II) Speciation at Coastal Water of Peninsular Malaysia. Oriental Journal of Chemistry, 34(4), 1858-1877.

Hussin, H., \& Khoso, A. (2017). Seaweed Cultivation and Coastal Communities in Malaysia: An overview. Asian Fisheries Science, 30, 87200.

Idris, H., \& Harun, R. (2004). Malaysia as a Maritime Situation: Prospects and Challenges. JATI-Journal of Southeast Asian Studies, 9, 19-31.

Islam, G. M., Noh, K. M., Sidique, S. F., Noh, A. F., \& Ali, A. (2014). Economic Impacts of Artificial Reefs on Small-Scale Fishers in Peninsular Malaysia. Human Ecology, 42(6), 989-998.

Johari, M. T. (1996). Status of The Demersal Fishery on The East Coast of Peninsular Malaysia. In Prosiding Persidangan Penyelidikan Perikanan 1996 (pp. 1-22). Pulau Pinang: Institute Penyelidikan Perikanan. Retrieved

from 
http://www.seafdec.org.my/v13/images/stories/pdf/DownloadPublicati on/Prosiding\%20Penyelidikan\%20Perikanan/Prosiding\%20Penyelidika n\%20Perikanan\%201996\%20Mohd\%20Taupek\%20M.N.,\%20Ibrahim\%2 $0 \mathrm{~J} . . \mathrm{pdf}$

Joseph, J. (2015). Modernization of Marine Fisheries Sector and Its Impact on the Livelihood of Traditional Fisher-Folk. Manpower Journal, 49(3/4), 4160.

Masud, M., Kari, F., Yahaya, S., \& Al-Amin, A. (2016). Livelihood Assets and Vulnerability Context of Marine Park Community Development in Malaysia. Social Indicators Research, 125(3), 771-792.

Nguyen, T. H. (2014). Transformation of Fish Corrals in Nha Phu Lagoon, Vietnam: Livelihood Changes and Implications. Australian Geographer, 45(3), 393-406.

Othman, J. (2004). A Critical Appraisal of the Strategy and Structure of the Fishermen's Associations in Malaysia. Reykjavic, Iceland: The United Nations University. Retrieved from file:///C:/Users/user/Downloads/LKIM\%20FO\%20Jamaludin.pdf

OXFAM. (1998). Achieving Maximum Impact: Oxfam's Strategy for Overcoming Poverty. Oxford: Oxfam.

Scoones, I. (1998). Sustainable Rural Livelihoods: A Framework for Analysis. IDS Working Paper 72. Brighton: Institute of Development Studies.

Zhong, L., Blaxland, M., \& Zuo, T. (2015). Without Rice, Even the Cleverest Housewife Cannot Cook: Sustainable Livelihoods Research in a Poor Chinese Village. Asian Social Work \& Policy Review, 9(1), 3-17. 